\title{
The laser propagation demonstration: a STEM-based outreach project
}

\section{Mark Spencer, Michael Steinbock, Milo Hyde, Michael Marciniak}

Mark F. Spencer, Michael J. Steinbock, Milo W. Hyde IV, Michael A. Marciniak, "The laser propagation demonstration: a STEM-based outreach project," Proc. SPIE 9188, Optics Education and Outreach III, 91880D (15 September 2014); doi: 10.1117/12.2060879

EDIE Event: SPIE Optical Engineering + Applications, 2014, San Diego, California, United States 


\title{
The Laser Propagation Demonstration: a STEM-based outreach project
}

Mark F. Spencer ${ }^{1}$, Michael J. Steinbock, Milo W. Hyde IV, and Michael A. Marciniak Air Force Institute of Technology, 2950 Hobson Way, Bldg 640, Wright Patterson AFB, OH 45433

\begin{abstract}
Investment in laser technology has led to significant advances in remote sensing, astronomy, industrial processing, and medical technology. To celebrate this rich heritage and promote public awareness in optics and photonics, the SPIE Student Chapter at the Air Force Institute of Technology (AFIT) developed the Laser Propagation Demonstration (LPD). This interactive demonstration serves as one of AFIT's legacy outreach projects for events involving education in science, technology, engineering, and mathematics (STEM). Initially developed with funding from a LaserFest grant awarded by SPIE in 2010, the goal was to develop a simple hands-on demonstration to highlight the optical effects of diffraction, refraction, and attenuation on laser propagation. Since then, the LPD has undergone several upgrades (thanks to the continued support from a 2012 SPIE Education Outreach Grant) to better highlight these optical phenomena and make it more engaging for a wider range of audiences. This paper celebrates the continued success of the LPD and shares the knowledge gained with an overview of its design and use in STEM-based outreach events.
\end{abstract}

Keywords: STEM, Outreach, SPIE Student Chapter, AFIT, Laser Propagation, Optics and Photonics Demonstration, Optics Outreach Games, Physics Education

\section{INTRODUCTION}

As seen in Fig. 1, the Laser Propagation Demonstration (LPD) is setup to interactively display the optical effects associated with coherent light propagation through atmospheric turbulence ${ }^{1,2}$. For this purpose, a green laser diode is set on the front end of a meter long optical rail. The laser beam from the green laser diode is then sent through various optical components placed along the optical rail to better highlight the optical effects that manifest from a rotating turbulence phase screen. After, the laser light meets a beam sampler set at a 45 degree angle. Approximately $95 \%$ of the laser light is transmitted through the beam sampler and is then projected onto a screen set on the back end of the optical rail. The reflected light from the beam sampler is then imaged onto a camera located on the back end of a separate optical rail also oriented at a 45 degree angle. This allows for the laser light to be seen on a laptop screen in addition to a projector when available.

Use of the optical rails allows for easy transportation and table-top setup of the LPD. It also provides added versatility in the fact that the demonstration builds on itself in a fun hands-on way. As such, the LPD is appropriate for both large and small crowds. With smaller crowds, a one-on-one approach is used. The interested student is able to adjust the various optical components themselves placed along the optical rail with the help of an Air Force Institute of Technology (AFIT) SPIE Student Chapter member. With a larger crowd, the various concepts are taught by an AFIT SPIE Student Chapter member. In either setting, accompanying handouts and posters boards allow for the audience to follow along with the explanations and ask questions to stimulate involvement at all levels. The LPD has the ability to appeal to a diverse crowd of inquisitive learners.

Section two of this paper provides an overview of the LPD's development. Here, the reader gets to visually see the LPD in action at various outreach events. Section three provides an overview of LPD's design and makes reference to a parts/price list located in the Appendix of this paper. Using this parts/price list, the interested reader can build their very own LPD! Section four then provides a conclusion for this paper with a roadmap for future upgrades that are currently in the mix.

\footnotetext{
1Email: msphotonics@gmail.com, Telephone: +1 (951) 323-3374
} 


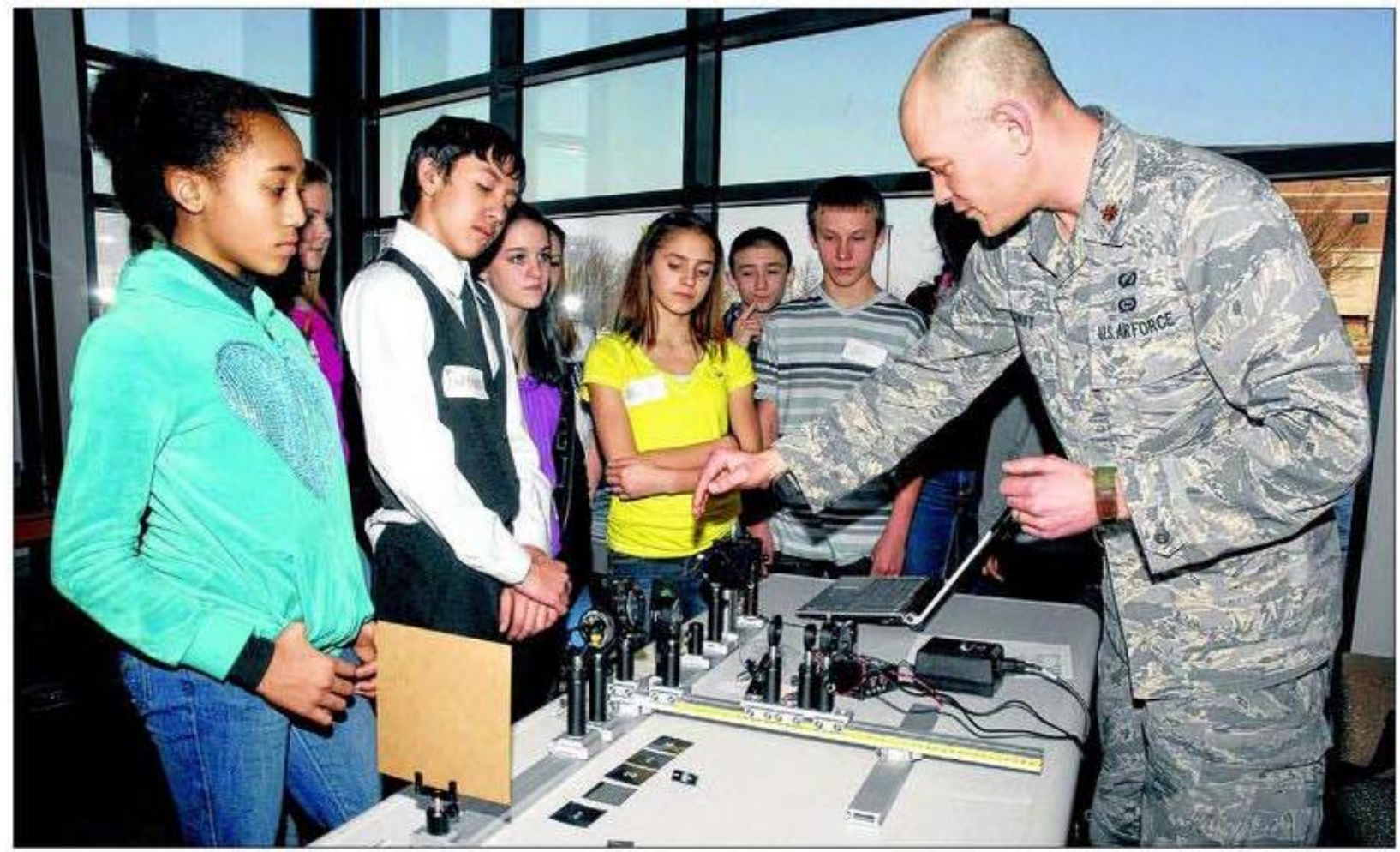

Figure 1. The LPD in action during a recent outreach event at AFIT (winter 2014). Here, an AFIT SPIE Student Chapter member demonstrates the optical effects associated with coherent light propagation through atmospheric turbulence. Over 100 students participated in this two-day outreach event, grades 6-8.

\section{OVERVIEW OF THE LPD'S DEVELOPMENT}

The LPD initially came into existence thanks to a LaserFest grant awarded by SPIE in 2010 for approximately $\$ 650$. Ongoing research at AFIT in directed energy ${ }^{3,4,5}$ and space situational awareness ${ }^{6,7,8}$ served as the inspiration for the LPD's design. As shown in Fig. 2, associated with this ongoing research is the idea that coherent light from a laser has to propagate through the atmosphere, which leads to multiple engineering constraints when dealing with military applications. With this in mind, the AFIT SPIE Student Chapter wanted to develop a way to demonstrate the optical effects of atmospheric turbulence on coherent light propagation ${ }^{1,2}$. Attendance at the 2010 Adaptive Optics Summer School (put on by the Center for Adaptive Optics at the University of California Santa Cruz) presented a clever way to simulate atmospheric turbulence in the laboratory9. Using this idea, the LPD's initial design was made part of a LaserFest lecture series held by AFIT (fall 2010), as seen in Fig. 3. Two distinguished researchers, Dr. Verdeyen ${ }^{10}$ and Dr. Hogge ${ }^{11}$, served as guest speakers. As required by the LaserFest grant, the SPIE Student Chapter developed handouts and poster boards to accompany the LPD (also seen in Fig. 3). Figures 4 and 5 give a more detailed view of the developed handouts, which are still in use to this day. Note that these handouts help to explain the underlying physics, experimental design, and military applications associated with the LPD.

In an effort to make the LPD more interactive and portable, it went through several design upgrades. As seen in Figs. 6 and 7, these design upgrades made an appearance at a multitude of outreach events around the Dayton, Ohio area. These outreach events include: Rosa Parks Middle School, the Boonshoft Museum, the AFIT campus, the 2013 TechFest at Sinclair Community College, the 2013 Junior Science and Humanities Symposium, and St. Xavier High School (to name a few). The LPD was also displayed at the 2011, 2012, and 2013 SPIE Optics Outreach Olympics/Games, as seen in Fig. 8. In 2011 and 2012 the LPD received third place bronze medals and in 2013 an honorable mention.

The reader should also note that the AFIT SPIE Student Chapter currently owns all of the LPD's parts outright thanks to continued support from a 2012 SPIE Education Outreach Grant for approximately $\$ 2500$. We greatly appreciate SPIE's support! 


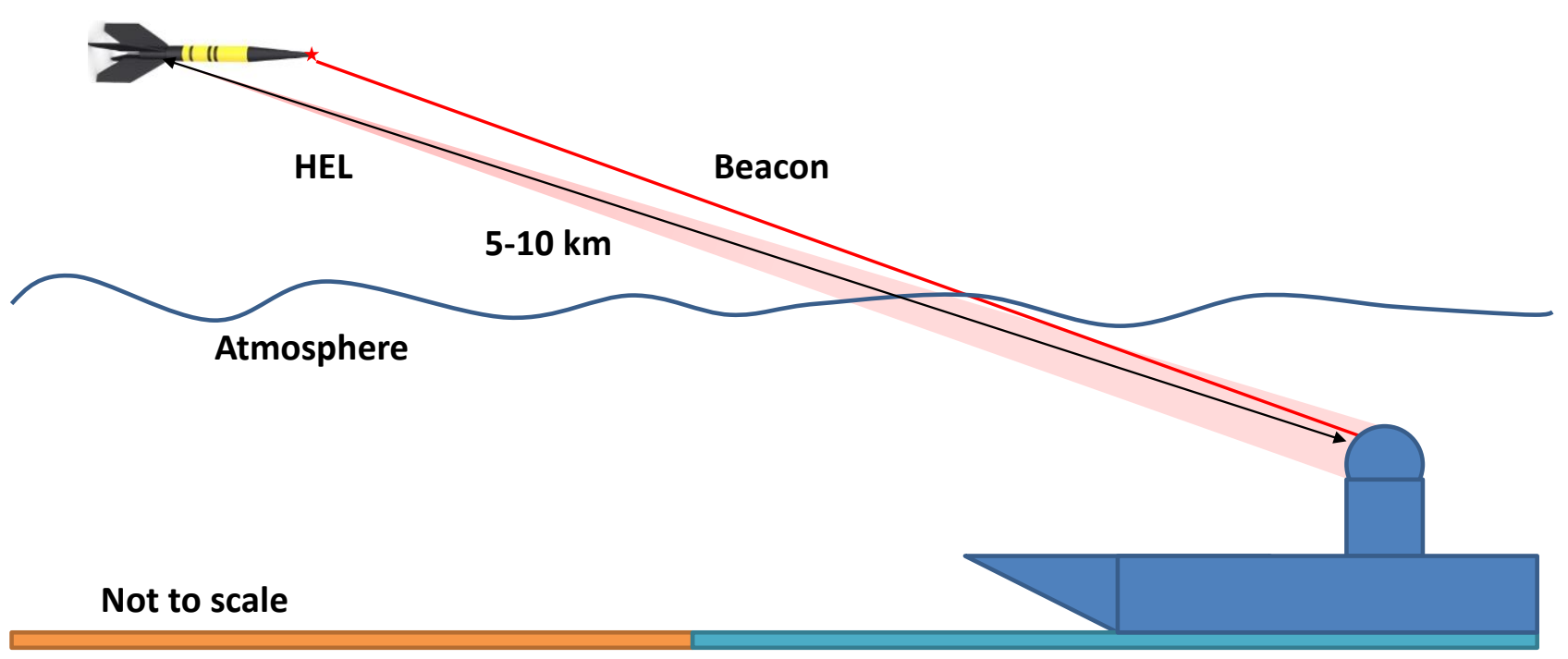

a.)

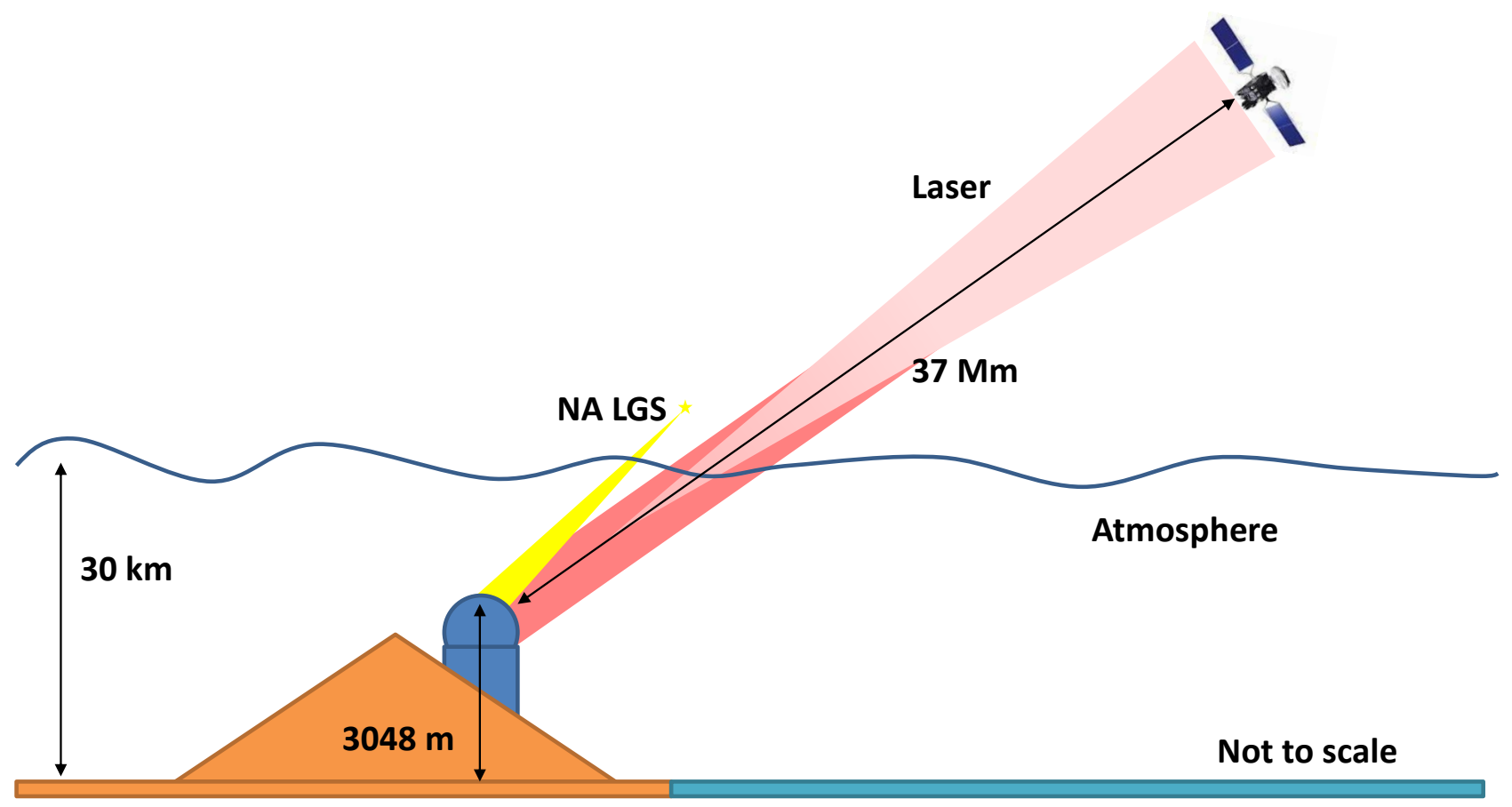

b.)

Figure 2. Description of ongoing research being performed at AFIT, which inspired the LPD's design. Specifically a.) describes a nominal directed energy engagement scenario where a high energy laser (HEL) engages a distant target, while b.) describes a nominal space situational awareness scenario where a laser illuminates a distant object. Associated with both of these descriptions is the idea that coherent light from a laser has to propagate through the atmosphere. 


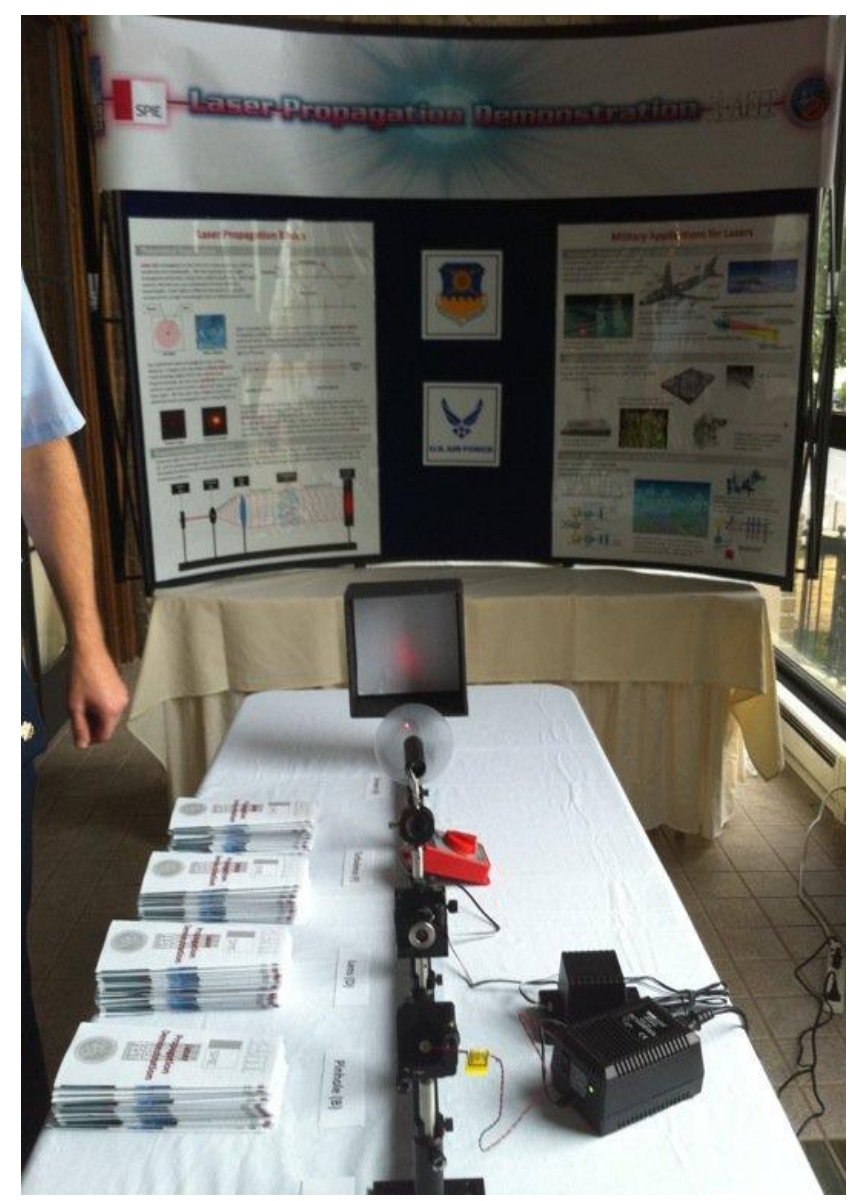

a.)

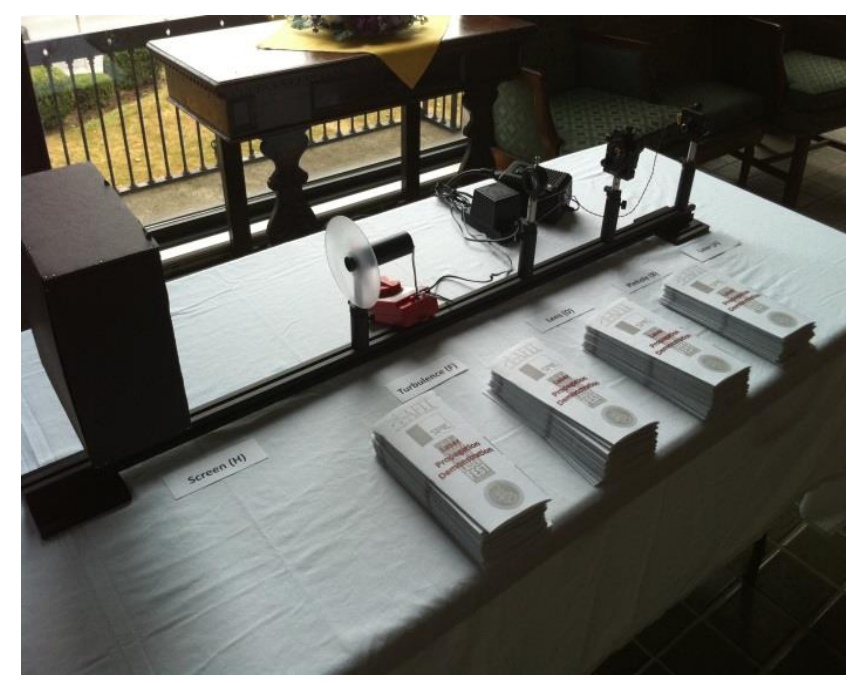

b.)

Figure 3. The initial design for the LPD. A red laser diode was set at the front end of a meter long optical rail. The laser beam from the red laser diode was then sent through a pinhole and collimating lens. A rotating turbulence phase screen was also added to the optical train to show the effects of a simulated atmosphere. a.) shows the LPD with the accompanying posters, whereas b.) shows the LPD with the accompanying handouts. See Figs. 4 and 5 for more detail. 

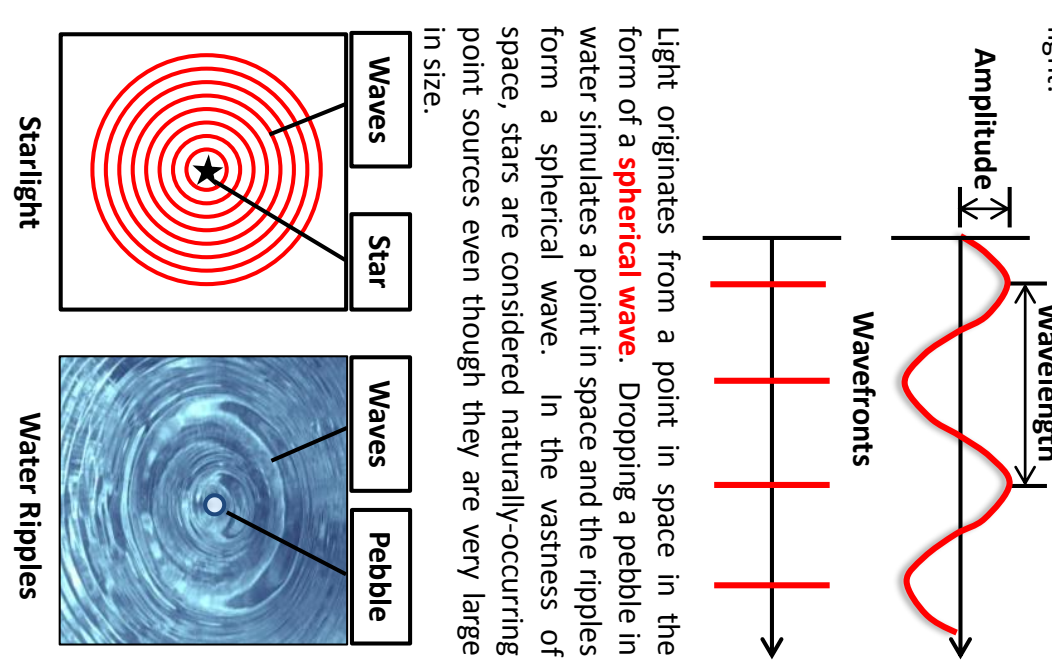

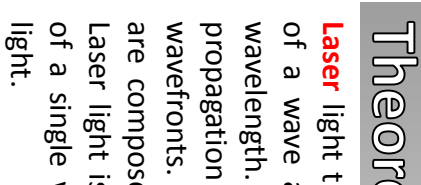

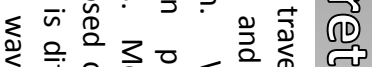

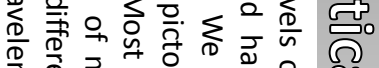

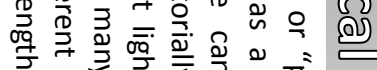

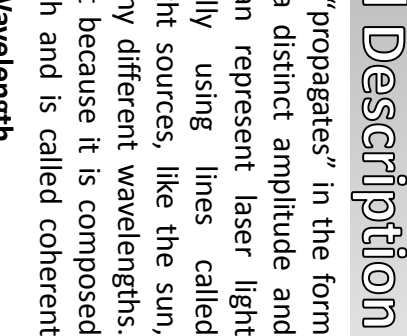
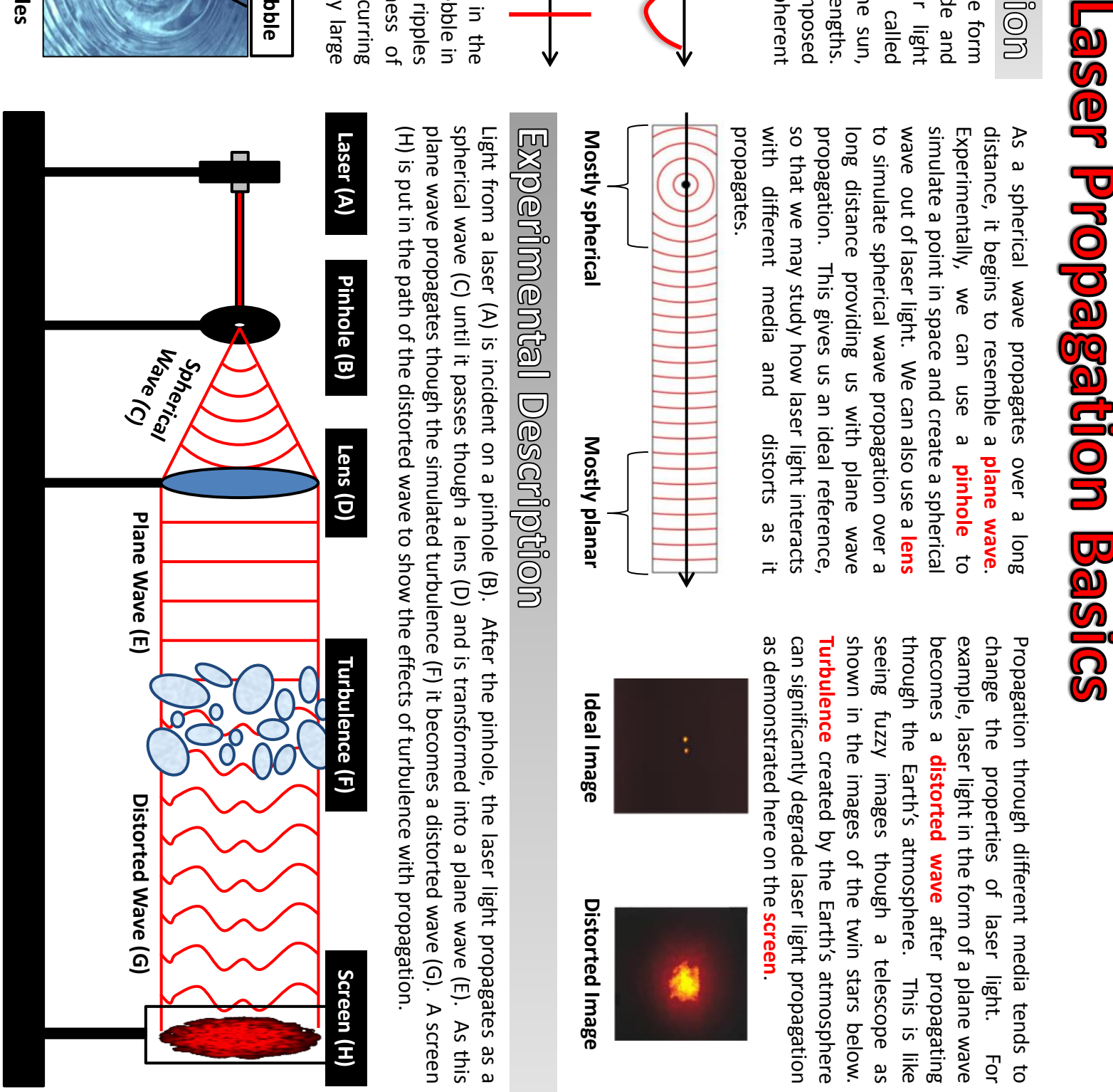

(1D)

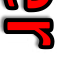

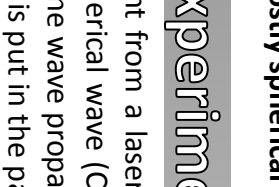

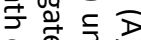

요욤

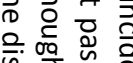
Oे

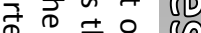

$\stackrel{2}{2}$.

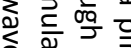

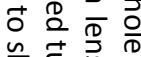

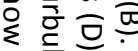

守贾高邑

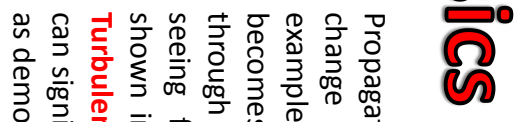

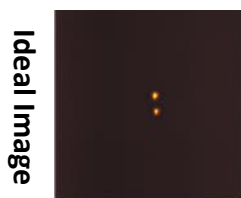

을 至

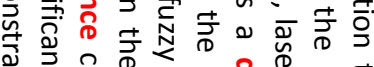

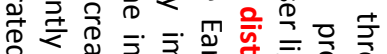

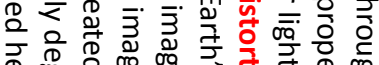

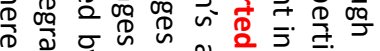

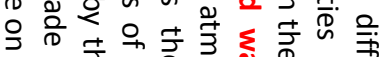

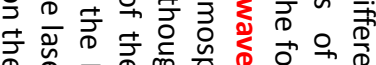

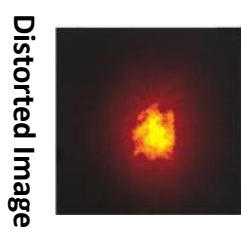

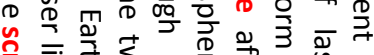

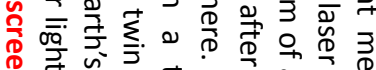

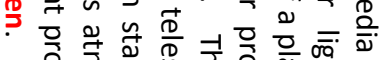

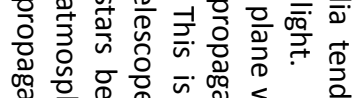

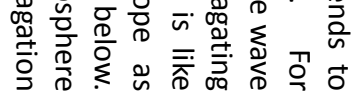

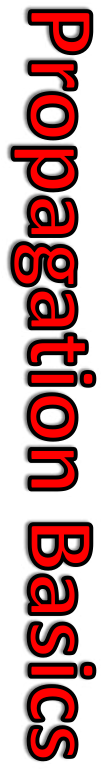

Figure 4. The handout associated with the LPD. This side of the handout gives theoretical and experimental explanations. 

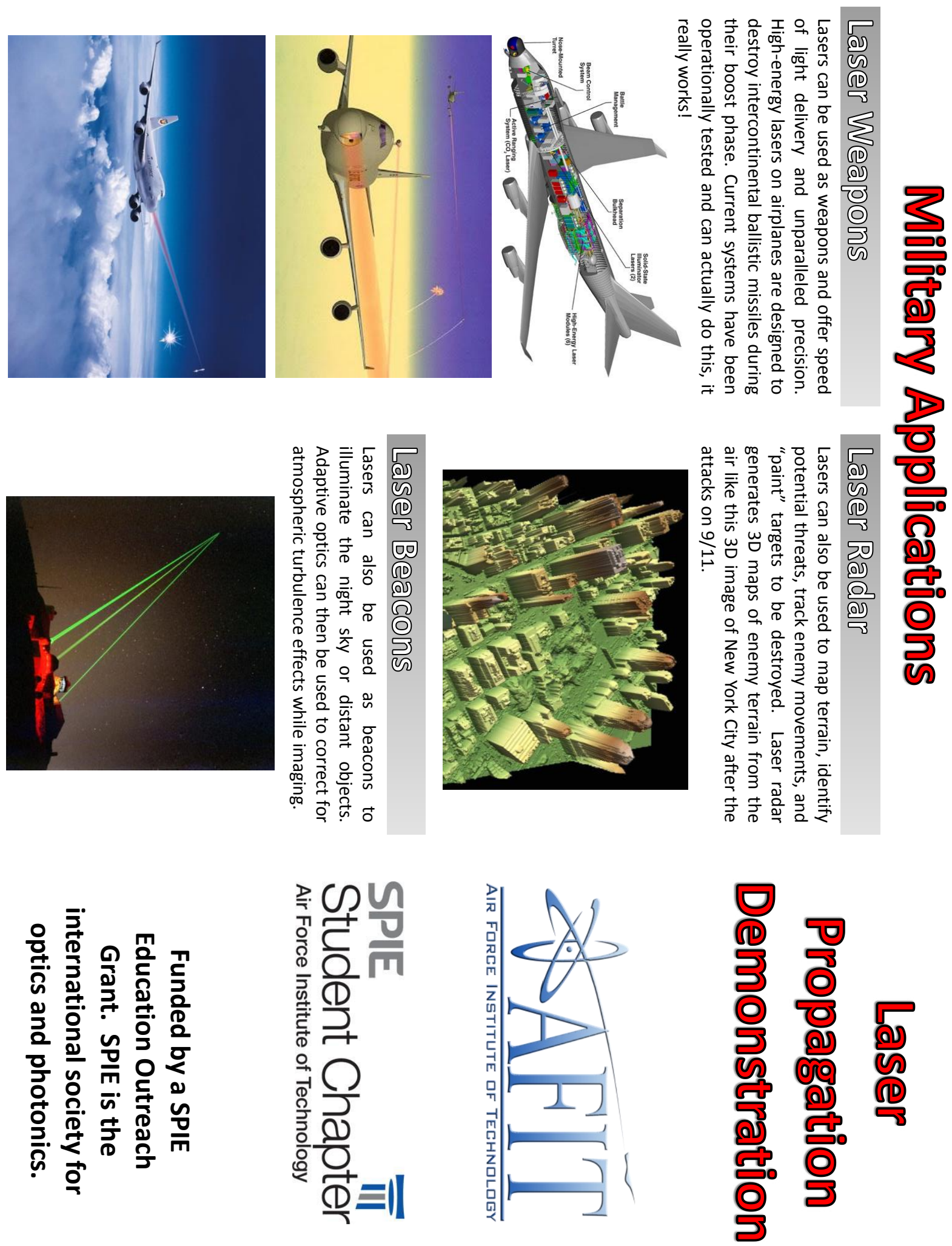

Figure 5. The handout associated with the LPD. This side of the handout introduces military applications. 


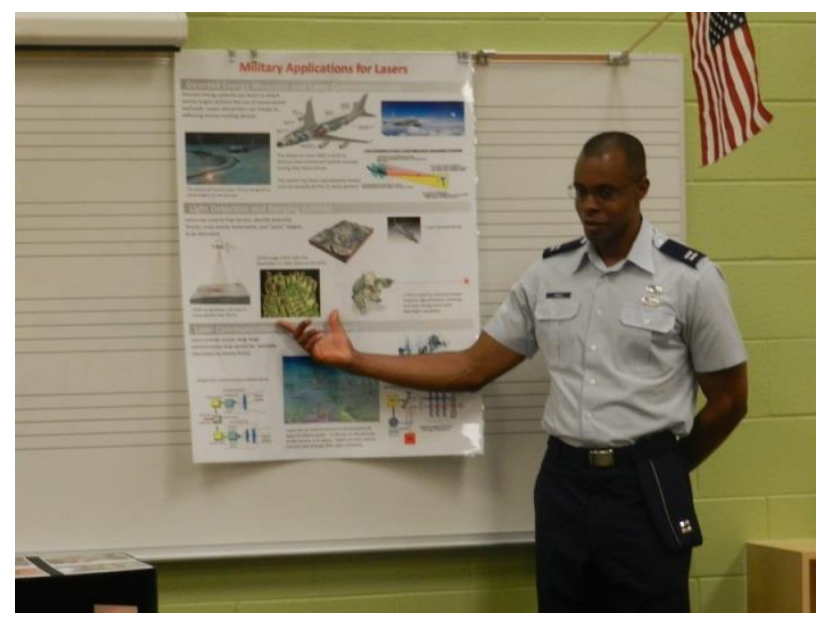

a.)

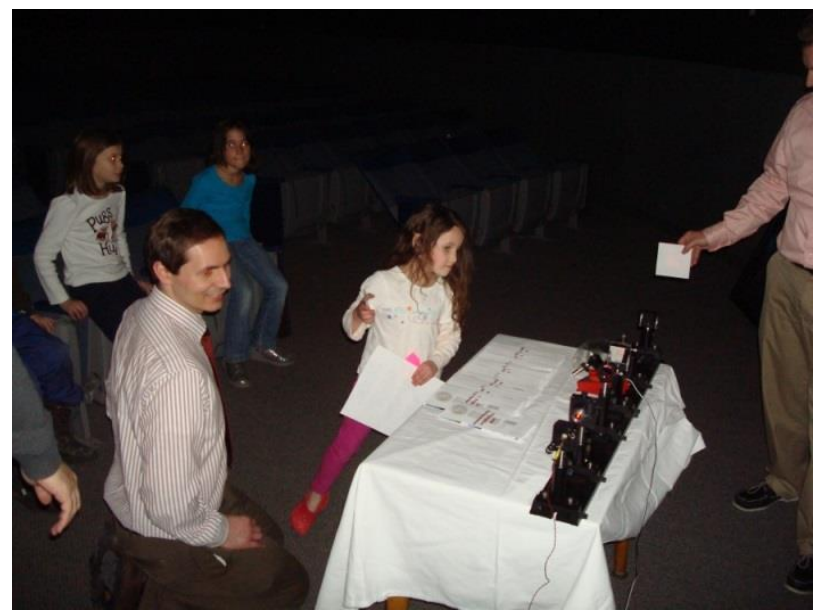

c.)

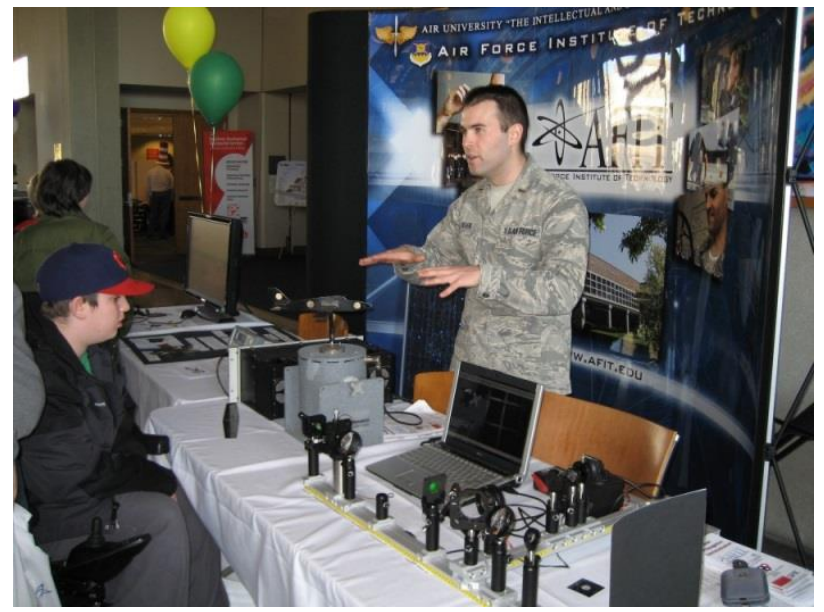

e.)

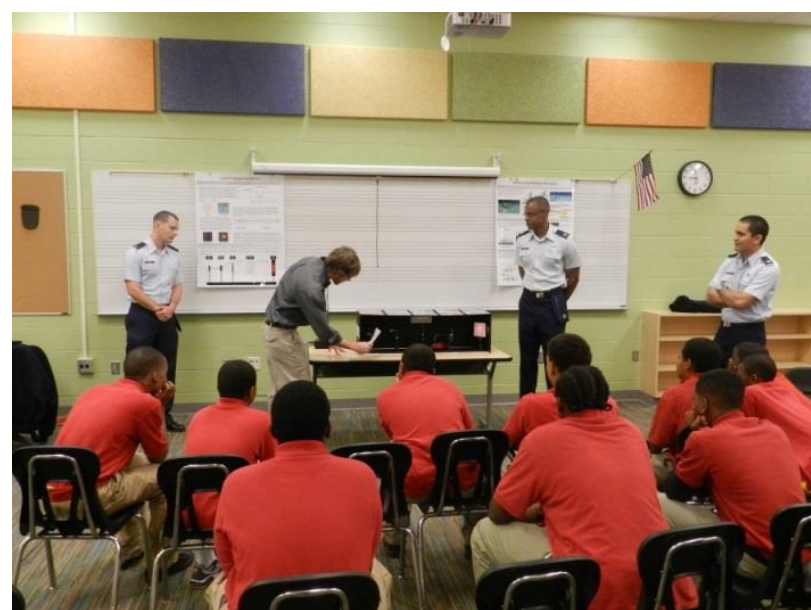

b.)

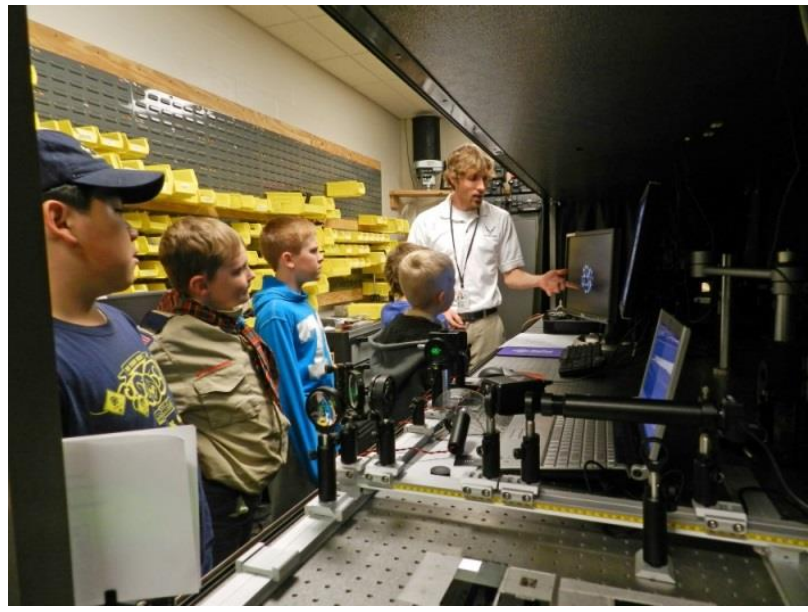

d.)

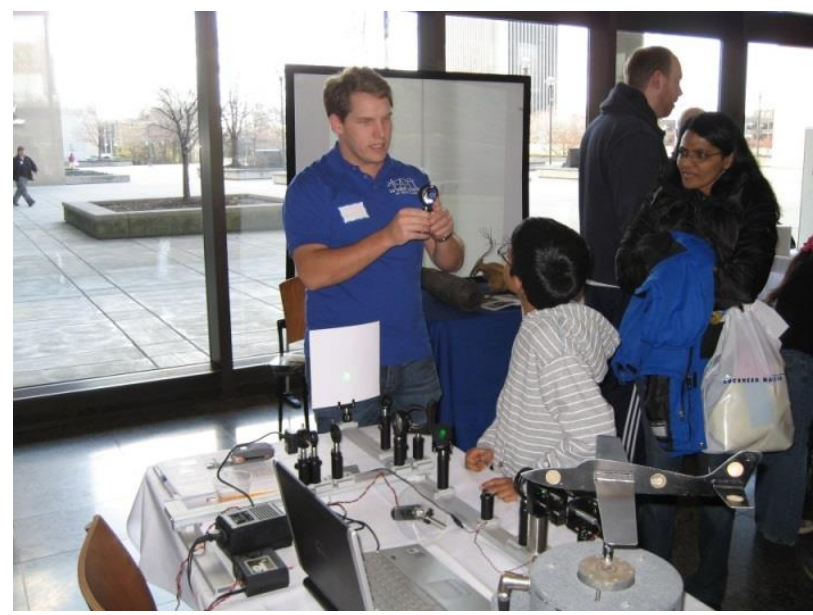

f.)

Figure 6. Various outreach events involving the LPD (2011-2013). a.) and b.) show the LPD at Rosa Parks Middle School with approximately 25 student participants, grades 6-8; c.) shows the LPD at the Boonshoft Museum with over 100 student participants, grades K-12; d.) shows the LPD at AFIT with a pack of Cub Scout visitors, grades 4-5; and e.) and f.) show the LPD at TechFest with over 2000 student participants, grades K-12. 


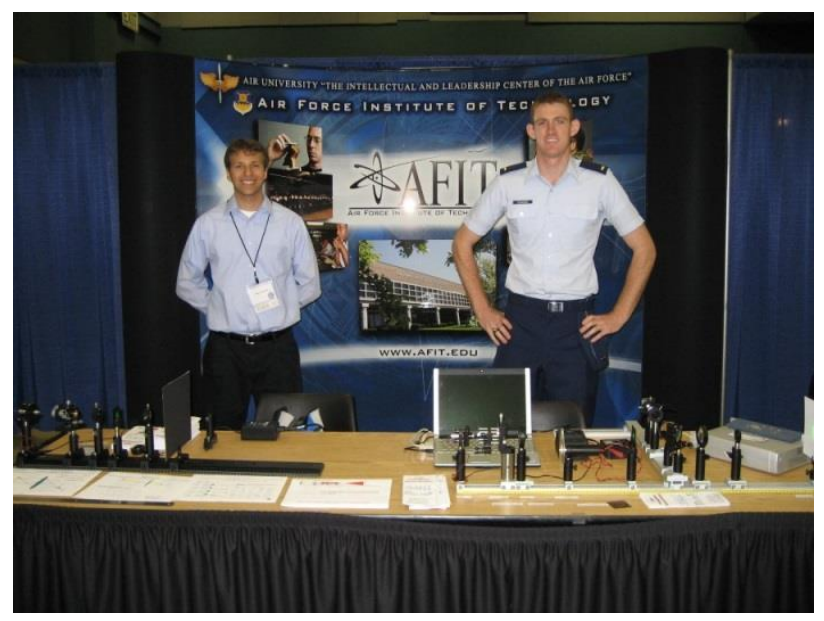

a.)

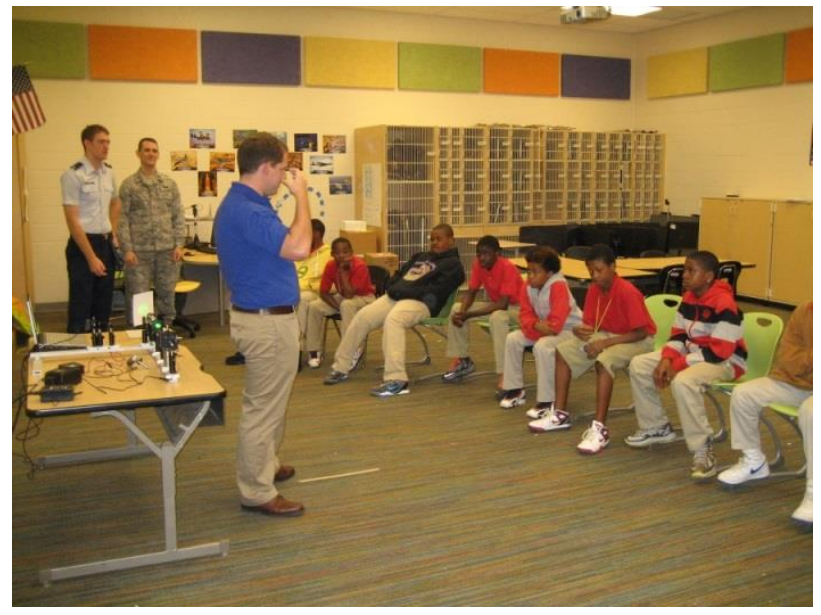

c.)

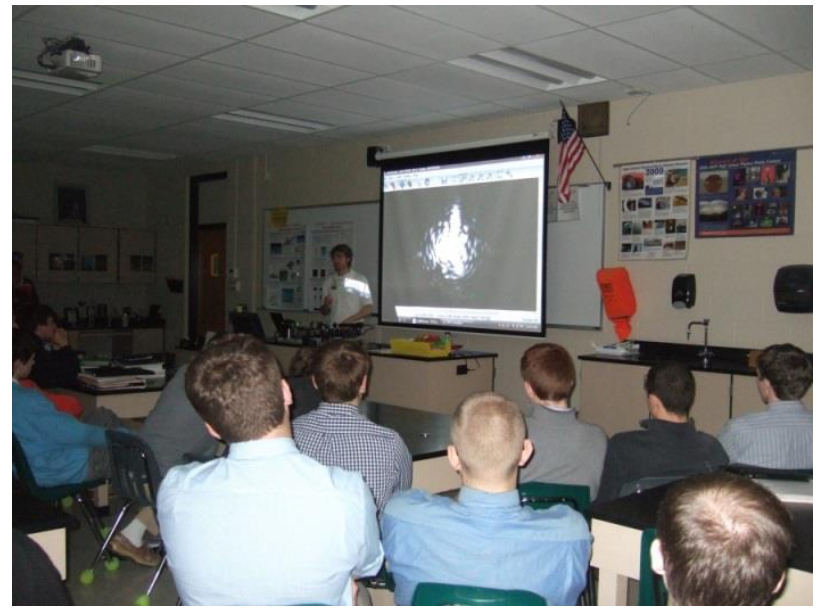

e.)

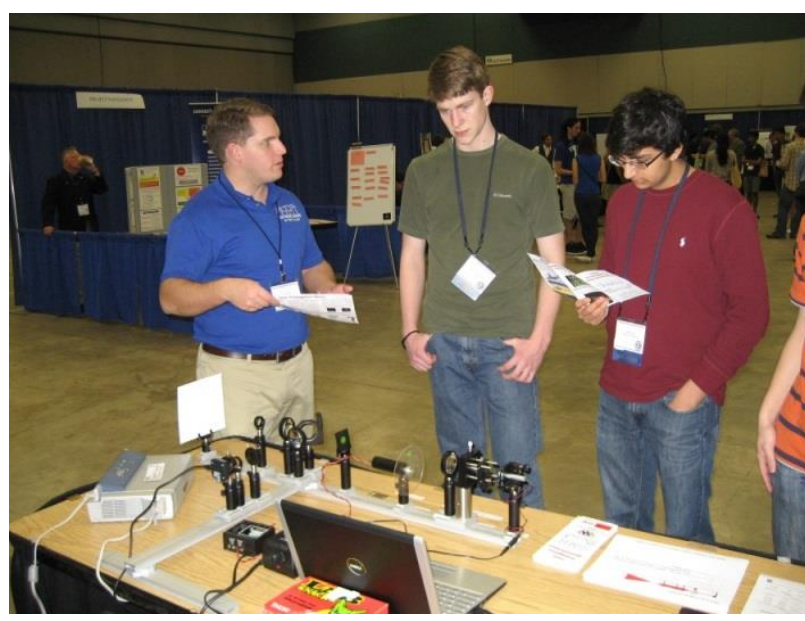

b.)

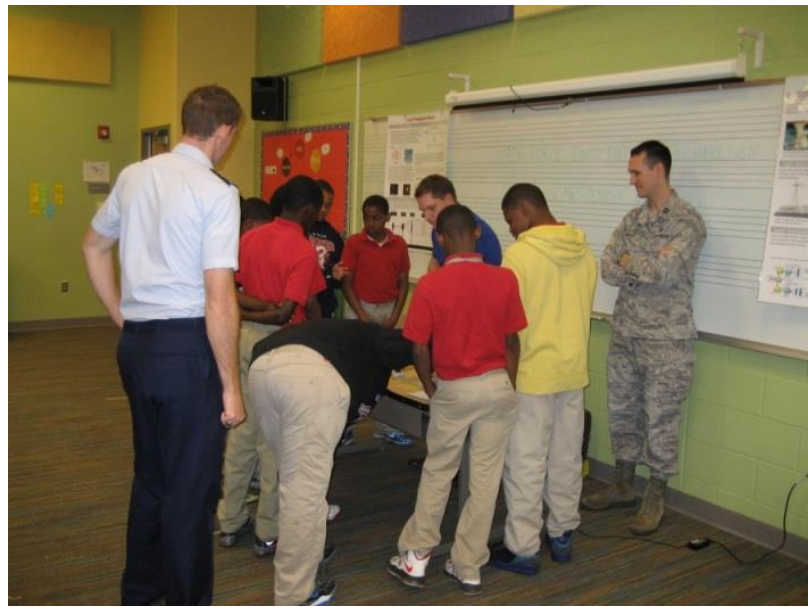

d.)

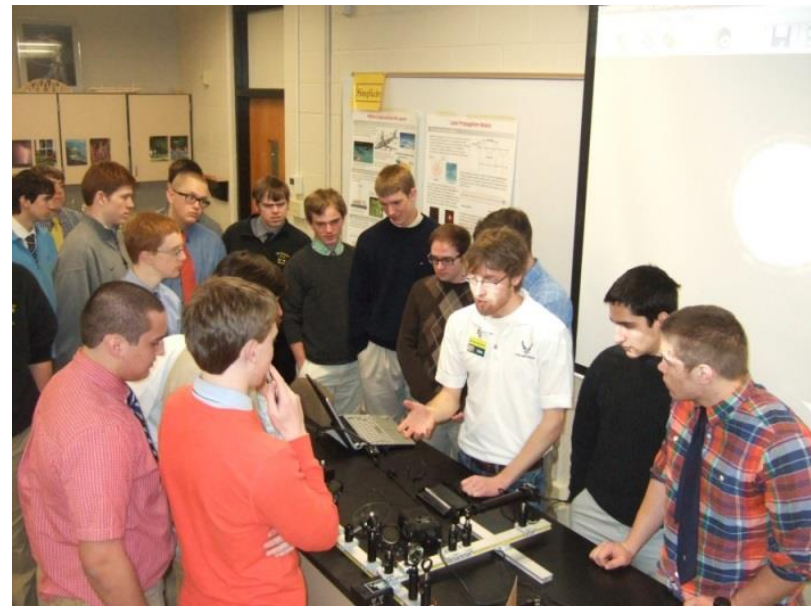

f.)

Figure 7. Various outreach events involving the LPD (2013-2014). a.) and b.) show the LPD at the Junior Science and Humanities Symposium with over 500 student participants, grades 9-12; c.) and d.) show the LPD at Rosa Parks Middle School with approximately 25 student participants, grades 6-8; and e.) and f.) show the LPD at St. Xavier High School with approximately 25 student participants, grades 11-12. 


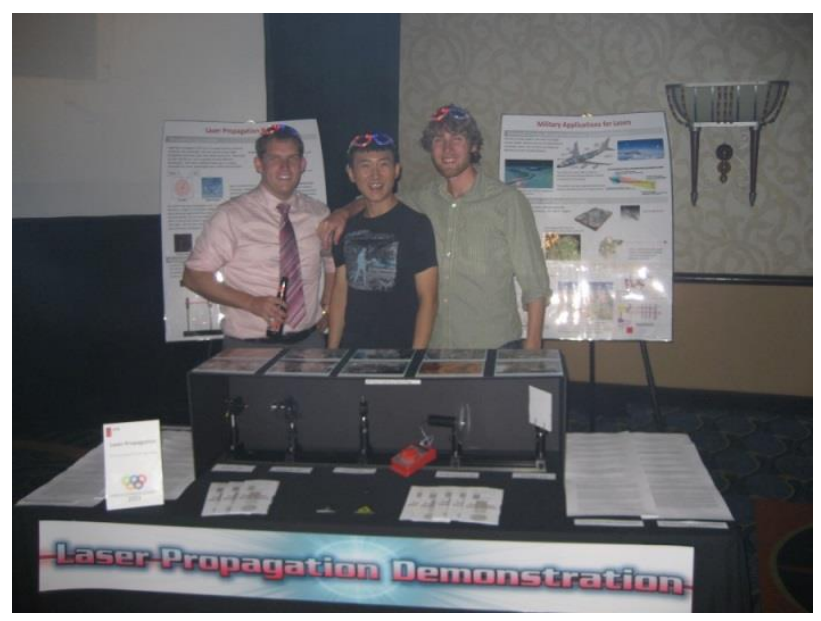

a.)

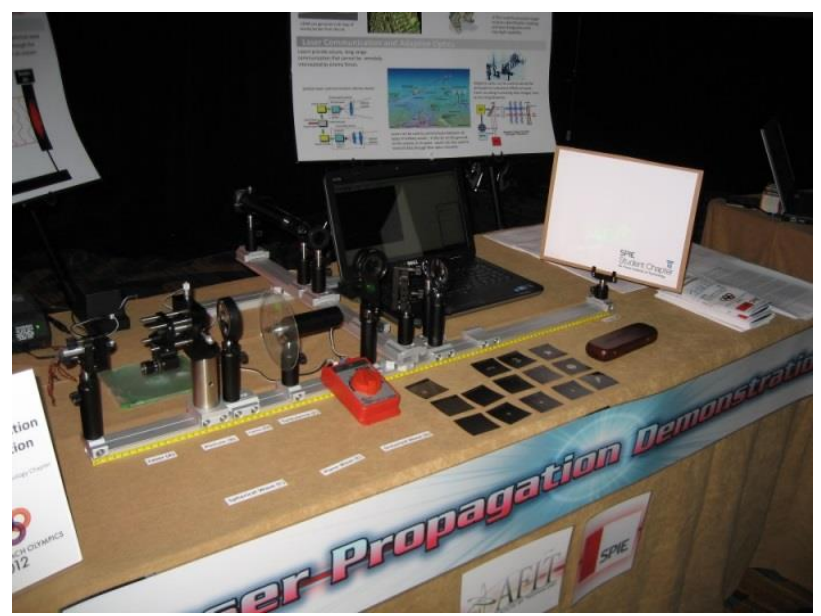

c.)

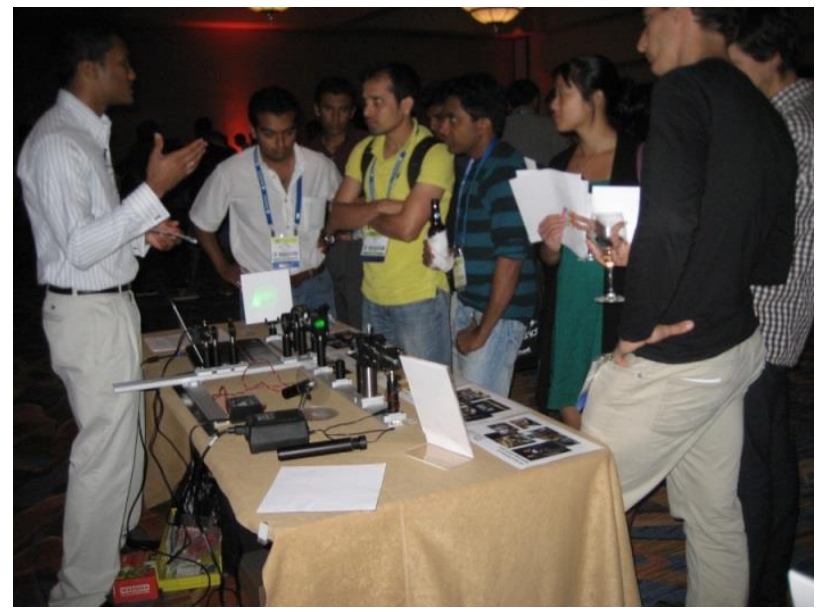

e.)

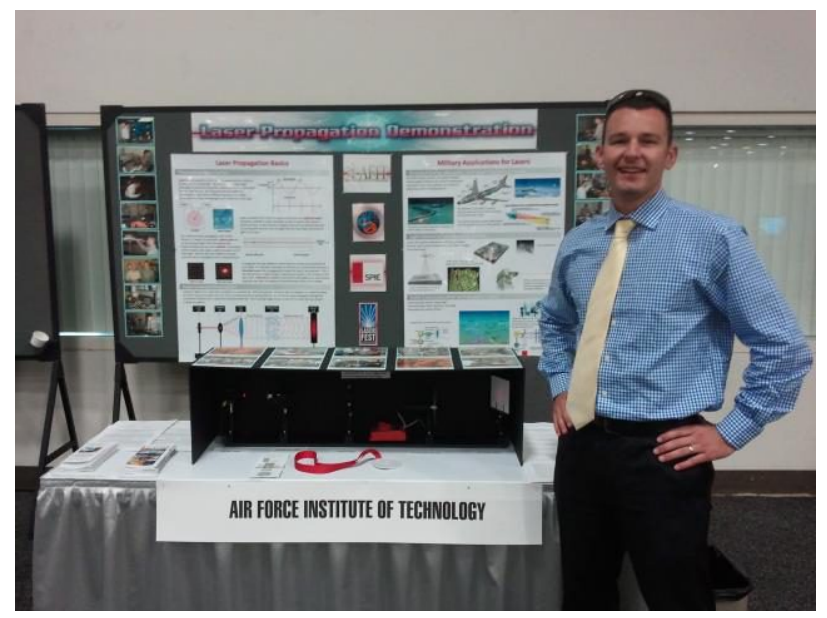

b.)

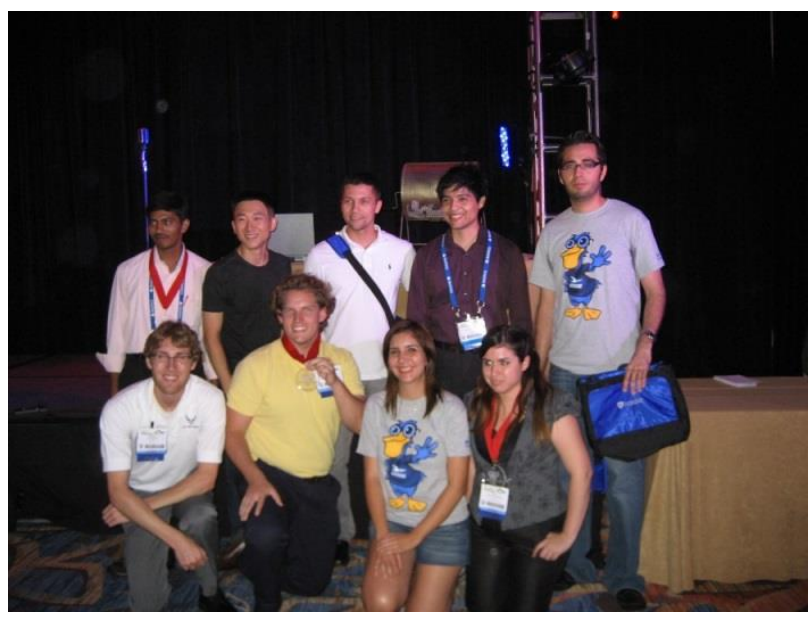

d.)

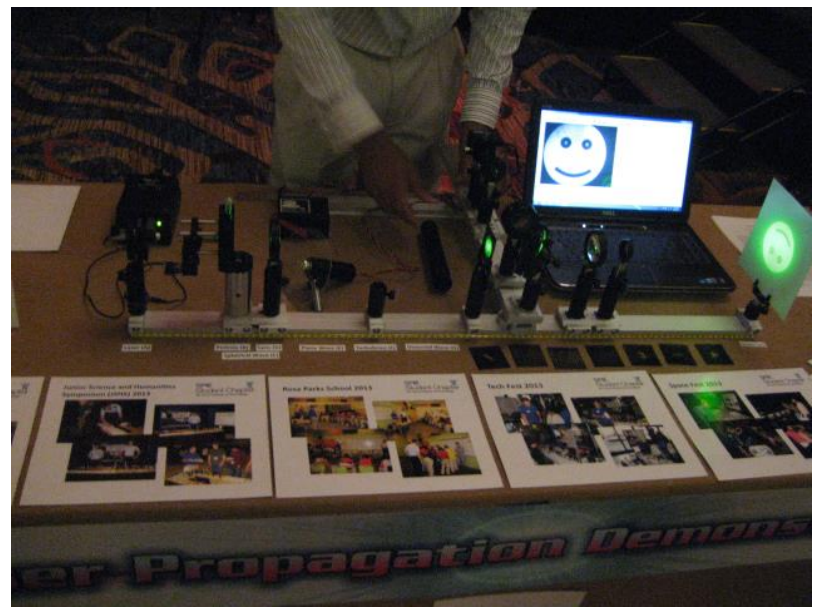

f.)

Figure 8. Participation in the 2011, 2012, and 2013 SPIE Optics Outreach Olympics/Games. a.) and b.) shows the 2011 LPD display, whereas c.) and d.) shows the 2012 LPD display - both displays won third place bronze metals. e.) and f.) shows the 2013 LPD display, which received a fourth place honorable mention. 


\section{OVERVIEW OF THE LPD'S DESIGN}

The LPD is a tried and true optics and photonics demonstration, and the AFIT SPIE Student Chapter hopes to share what we have learned through its development. The Appendix contains a parts/price list for all of the LPD's components. Assuming, that you have access to an optics lab with the various tools required for assembly, you can build a similar upgraded demonstration for around \$3300; however, a basic design can also be constructed for less than \$2000! Figure 9 below shows a description for both designs, which primarily use optical components from Thorlabs. The only custom parts included in the LPD's design are the turbulence phase screen and the amplitude masks, as shown in Fig. 10.

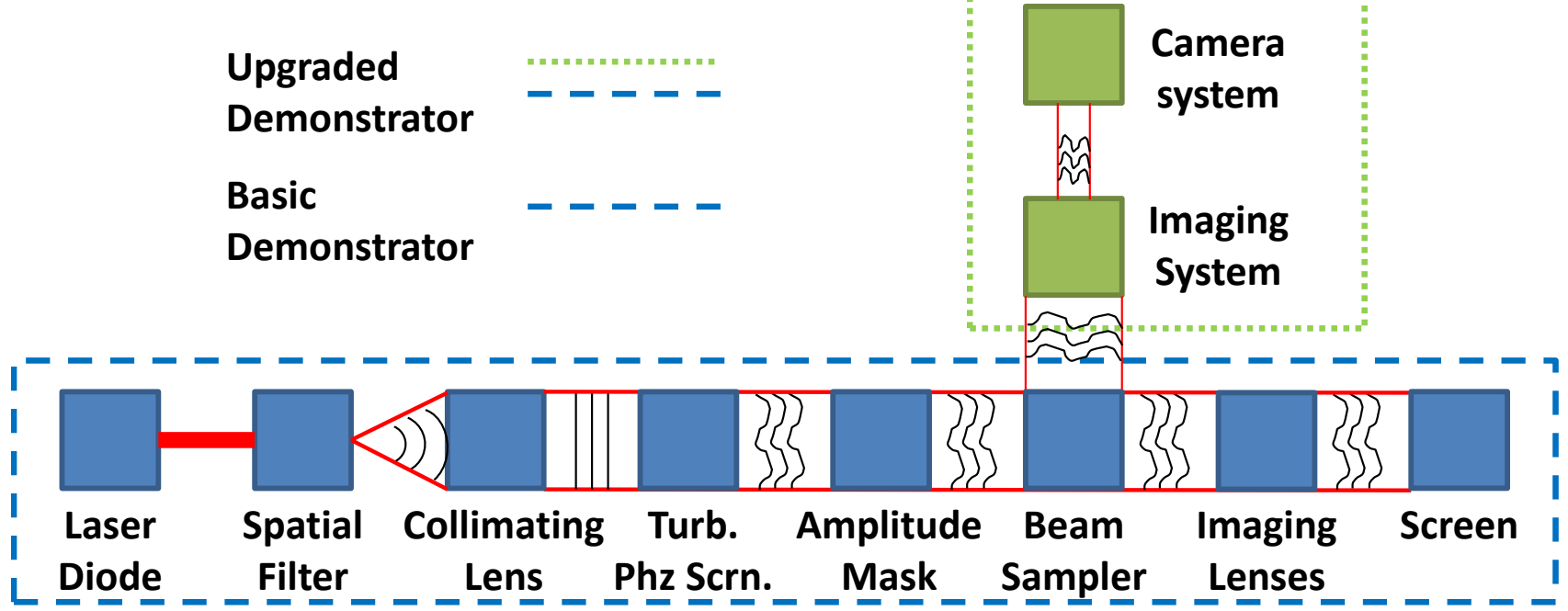

Figure 9. Description of the LPD. A parts list for both the upgraded and basic designs is given in the Appendix

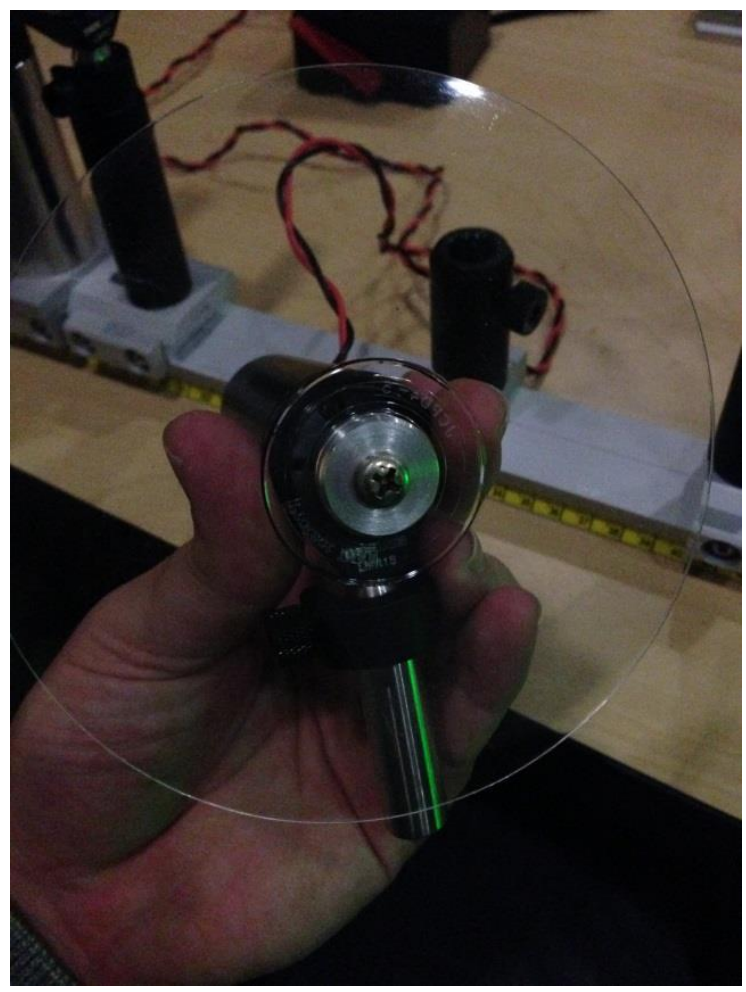

a.)

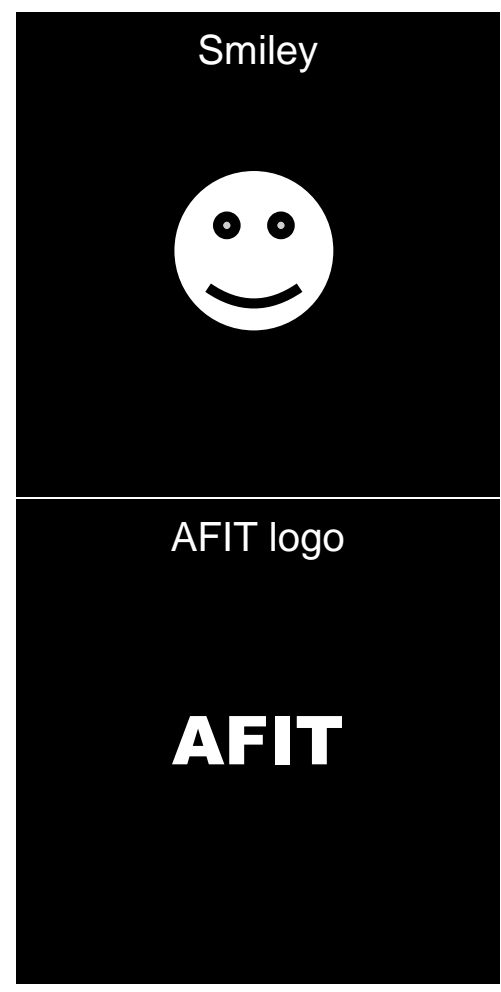

b.)

Figure 10. A detailed look at a.) the turbulence phase screen and b.) the amplitude masks used with the LPD. 
Both the turbulence phase screen and the amplitude masks are easy to make in practice. For example, to make the turbulence phase screen, the interested reader should use a clear cd that comes on the top or bottom of a stack of blank cds. Proceed to lightly coat it with hair spray or clear acrylic spray paint ${ }^{9,12}$. This causes changes in the index of refraction which distorts the phase of the incident laser light. Upon propagation, this gives rise to constructive and destructive interference, also known as scintillation, and distortion upon imaging ${ }^{1,2}$. In addition, to make the amplitude masks, simply print the examples provided in Fig. 10 on clear transparencies or design your own using Microsoft PowerPoint. It's that easy!

\section{CONCLUSION}

This paper reviews the success of the LPD-AFIT's legacy outreach effort in optics and photonics. It is our hope that the interested reader can improve our design and share it with the STEM-based outreach community. The SPIE Student Chapter at AFIT plans to continually upgrade the LPD as well. In the near future, we plan to finish building robust carrying cases so that transportation of the LPD is even easier! With that said, if you have questions, please do not hesitate to ask-you may contact the first author via the info given above.

The views expressed in this paper are those of the authors and do not reflect the official policy or position of the U.S. Air Force, Department of Defense, or the U.S. government.

\section{APPENDIX}

Table 1 below gives a parts/price list for the upgraded LPD design given in Fig. 9, whereas Table 2 gives a parts/price list for the basic LPD design.

Table 1. Parts/price list - upgraded LPD design.

\begin{tabular}{|c|c|c|c|c|}
\hline Thorlabs Rails & Part Number & Quantity & Price & QxP \\
\hline XT66 Series Double Dovetail, $L=1000$ mm & XT66DP-1000 & 2 & $\$ 84.00$ & $\$ 168.00$ \\
\hline XT66 Cross Clamp & XT66CC & 2 & $\$ 49.50$ & $\$ 99.00$ \\
\hline XT66 Double Dovetail Clamp, $20 \mathrm{~mm}$ & XT66C1 & 5 & $\$ 16.50$ & $\$ 82.50$ \\
\hline Short Dovetail with $1 / 4 "-20$ Tap, $20 \mathrm{~mm}$ Long & XT66DE1 & 5 & $\$ 9.50$ & $\$ 47.50$ \\
\hline XT66 Double Dovetail Clamp, $40 \mathrm{~mm}$ & XT66C2 & 8 & $\$ 18.30$ & $\$ 146.40$ \\
\hline $\begin{array}{l}\text { Dovetail with Three X-Axis Counterbore Slots, } 50 \text { mm } \\
\text { Long }\end{array}$ & XT66D2 & 7 & $\$ 16.00$ & $\$ 112.00$ \\
\hline $\begin{array}{l}\text { Dovetail Mounting Platform for } 66 \mathrm{~mm} \text { Optical Rails, } 40 \\
\text { mm Long }\end{array}$ & XT66D2-40 & 1 & $\$ 14.00$ & $\$ 14.00$ \\
\hline Low-Profile T-Nut (1/4"-20), 10 per Pack & XE25T3 & 1 & $\$ 9.60$ & $\$ 9.60$ \\
\hline \multicolumn{4}{|r|}{ Sub Tot } & $\$ 679.00$ \\
\hline Thorlabs Posts & Part Number & Quantity & Price & QxP \\
\hline $\begin{array}{l}\text { Post Holder with Spring-Loaded Hex Locking } \\
\text { Thumbscrew, L = 3.00" }\end{array}$ & PH3 & 5 & $\$ 8.27$ & $\$ 41.35$ \\
\hline $\begin{array}{l}\text { Ø1/2" x 3" Stainless Steel Optical Post, 8-32 Stud, 1/4"-20 } \\
\text { Tapped Hole }\end{array}$ & TR3 & 5 & $\$ 5.42$ & $\$ 27.10$ \\
\hline $\begin{array}{l}\text { Post Holder with Spring-Loaded Hex Locking } \\
\text { Thumbscrew, L = 2.00" }\end{array}$ & PH2 & 6 & $\$ 7.70$ & $\$ 46.20$ \\
\hline $\begin{array}{l}\text { Ø1/2" x 2" Stainless Steel Optical Post, 8-32 Stud, 1/4"-20 } \\
\text { Tapped Hole }\end{array}$ & TR2 & 6 & $\$ 5.19$ & $\$ 31.14$ \\
\hline $\begin{array}{l}\text { Post Holder with Spring-Loaded Hex Locking } \\
\text { Thumbscrew, L = 1.00" }\end{array}$ & PH1 & 1 & $\$ 7.03$ & $\$ 7.03$ \\
\hline $\begin{array}{l}\text { Ø1/2" x 1" Stainless Steel Optical Post, 8-32 Stud, 1/4"-20 } \\
\text { Tapped Hole }\end{array}$ & TR1 & 1 & $\$ 4.74$ & $\$ 4.74$ \\
\hline
\end{tabular}




\begin{tabular}{|c|c|c|c|c|}
\hline & & & Sub Tot & $\$ 157.56$ \\
\hline Thorlabs Laser Diode & Part Number & Quantity & Price & QxP \\
\hline $\begin{array}{l}\text { Collimated Laser Diode Module, } 532 \mathrm{~nm}, 4.5 \mathrm{~mW} \text {, Round } \\
\text { Beam }\end{array}$ & CP532 & 1 & $\$ 155.00$ & $\$ 155.00$ \\
\hline SM1 Adapter for Ø11 mm Collimators & AD11F & 1 & $\$ 27.00$ & $\$ 27.00$ \\
\hline SM1-Threaded Kinematic Mount for Thin Ø1" Optics & KM100T & 1 & $\$ 64.00$ & $\$ 64.00$ \\
\hline \multirow[t]{2}{*}{5 VDC Regulated Power Supply, 2.5 mm Phono Plug } & LDS5 & 1 & $\$ 83.35$ & $\$ 83.35$ \\
\hline & & & Sub Tot & $\$ 329.35$ \\
\hline Thorlabs Spatial Filter & Part Number & Quantity & Price & QxP \\
\hline XY Translator with Micrometer Drives & ST1XY-S & 1 & $\$ 344.60$ & $\$ 344.60$ \\
\hline Z-Axis Translation Mount, One Retaining Ring Included & SM1Z & 1 & $\$ 176.00$ & $\$ 176.00$ \\
\hline $30 \mathrm{~mm}$ Cage System Alignment Plate with Ø1 mm Hole & CPA1 & 1 & $\$ 12.00$ & $\$ 12.00$ \\
\hline Cage Assembly Rod, 2" Long, Ø6 mm, Qty. 1 & ER2 & 4 & $\$ 6.10$ & $\$ 24.40$ \\
\hline Extended RMS to M9 x 0.5 Adapter & E09RMS & 1 & $\$ 32.00$ & $\$ 32.00$ \\
\hline $\begin{array}{l}\text { Adapter with External SM1 Threads and Internal RMS } \\
\text { Threads }\end{array}$ & SM1A3 & 1 & $\$ 16.75$ & $\$ 16.75$ \\
\hline $\begin{array}{l}\text { Ø1.5" Post Mounting Adapter, 1/4" Clearance / \#8 } \\
\text { Clearance }\end{array}$ & MA2 & 1 & $\$ 16.00$ & $\$ 16.00$ \\
\hline Ø1.5" Mounting Post, Length=3", 1/4"-20 Taps & P3 & 1 & $\$ 33.00$ & $\$ 33.00$ \\
\hline $\begin{array}{l}\text { Ø10 } \mu \mathrm{m} \text { Mounted Pinhole, Ideal For Building Spatial } \\
\text { Filters }\end{array}$ & P10S & 1 & $\$ 70.00$ & $\$ 70.00$ \\
\hline $\begin{array}{l}f=11.0 \mathrm{~mm}, \mathrm{NA}=0.26, \text { MountedAspheric Lens, AR: 350- } \\
700 \mathrm{~nm}\end{array}$ & A220TM-A & 1 & $\$ 87.00$ & $\$ 87.00$ \\
\hline & & & Sub Tot & $\$ 811.75$ \\
\hline Thorlabs Lenses and Lens Mounts & Part Number & Quantity & Price & QxP \\
\hline Lens Mount for Ø2" Optics, One Retaining Ring Included & LMR2 & 3 & $\$ 23.50$ & $\$ 70.50$ \\
\hline Lens Mount for Ø1" Optics, One Retaining Ring Included & LMR1 & 3 & $\$ 15.70$ & $\$ 47.10$ \\
\hline $\begin{array}{l}\text { N-BK7 Plano-Convex Lens, Ø1", f = } 25.4 \text { mm, ARC: } 350- \\
700 \text { nm }\end{array}$ & LA1951-A & 1 & $\$ 31.80$ & $\$ 31.80$ \\
\hline $\begin{array}{l}\text { N-BK7 Plano-Convex Lens, Ø1", } \mathrm{f}=50.0 \mathrm{~mm}, \mathrm{ARC}: 350 \text { - } \\
700 \mathrm{~nm}\end{array}$ & LA1131-A & 1 & $\$ 29.80$ & $\$ 29.80$ \\
\hline $\begin{array}{l}\text { N-BK7 Plano-Convex Lens, Ø1", f = } 200.0 \text { mm, ARC: 350- } \\
700 \text { nm }\end{array}$ & LA1708-A & 1 & $\$ 27.90$ & $\$ 27.90$ \\
\hline $\begin{array}{l}\text { N-BK7 Plano-Convex Lens, } \varnothing 50.8 \mathrm{~mm}, \mathrm{f}=75.0 \mathrm{~mm}, \text { ARC: } \\
350-700 \mathrm{~nm}\end{array}$ & LA1145-A & 2 & $\$ 39.80$ & $\$ 79.60$ \\
\hline $\begin{array}{l}\text { N-BK7 Plano-Convex Lens, } \emptyset 50.8 \mathrm{~mm}, \mathrm{f}=150.0 \mathrm{~mm} \\
\text { ARC: } 350-700 \mathrm{~nm}\end{array}$ & LA1417-A & 1 & $\$ 35.80$ & $\$ 35.80$ \\
\hline & & & Sub Tot & $\$ 322.50$ \\
\hline Thorlabs Beam Sampler & Part Number & Quantity & Price & QxP \\
\hline Ø2" UVFS Beam Sampler, ARC: $350-700 \mathrm{~nm}, \mathrm{t}=\mathbf{8} \mathrm{mm}$ & BSF20-A & 1 & $\$ 88.10$ & $\$ 88.10$ \\
\hline Kinematic Mount for Ø2" Optics & KM200 & 1 & $\$ 74.10$ & $\$ 74.10$ \\
\hline & & & Sub Tot & $\$ 162.20$ \\
\hline Thorlabs Camera System & Part Number & Quantity & Price & QxP \\
\hline Translating Lens Mount for Ø1" Optics & LM1XY & 1 & $\$ 133.70$ & $\$ 133.70$ \\
\hline $\begin{array}{l}\text { High Resolution USB2.0 CMOS Camera, } 1280 \text { x 1024, } \\
\text { Monochrome }\end{array}$ & DCC1545M & 1 & $\$ 345.00$ & $\$ 345.00$ \\
\hline $\begin{array}{l}\text { Ø1" SM1 Rotating Adjustable Focusing Element, L = 1", } \\
\text { 0.81" Travel }\end{array}$ & SM1V10 & 1 & $\$ 32.60$ & $\$ 32.60$ \\
\hline
\end{tabular}


6" Extension Tube for SM1 Lens Tube, One Retaining Ring Included

\begin{tabular}{|c|c|c|c|}
\hline SM1E60 & 1 & $\$ 44.00$ & $\$ 44.00$ \\
\hline & \multicolumn{2}{|r|}{ Sub Tot } & $\$ 555.30$ \\
\hline Part Number & Quantity & Price & QxP \\
\hline SM1L30 & 1 & $\$ 12.16$ & $\$ 12.16$ \\
\hline SM130 & 1 & $\$ 25.75$ & $\$ 25.75$ \\
\hline FH2 & 2 & $\$ 18.00$ & $\$ 36.00$ \\
\hline ID25Z & 1 & $\$ 65.00$ & $\$ 65.00$ \\
\hline SM2D25 & 1 & $\$ 84.70$ & $\$ 84.70$ \\
\hline & \multicolumn{2}{|r|}{ Sub Tot } & $\$ 223.61$ \\
\hline Part Number & Quantity & Price & QxP \\
\hline N/A & 1 & $\$ 10.00$ & $\$ 10.00$ \\
\hline N/A & 1 & $\$ 25.00$ & $\$ 25.00$ \\
\hline N/A & 1 & $\$ 10.00$ & $\$ 10.00$ \\
\hline N/A & 1 & $\$ 10.00$ & $\$ 10.00$ \\
\hline & & Sub Tot & $\$ 55.00$ \\
\hline & & Total & $\$ 3,296.27$ \\
\hline
\end{tabular}

Table 2. Parts/price List-basic LPD design

\begin{tabular}{|c|c|c|c|c|}
\hline Thorlabs Rails & Part Number & Quantity & Price & QxP \\
\hline XT66 Series Double Dovetail, $\mathrm{L}=1000 \mathrm{~mm}$ & XT66DP-1000 & 1 & $\$ 84.00$ & $\$ 84.00$ \\
\hline XT66 Double Dovetail Clamp, 20 mm & XT66C1 & 7 & $\$ 16.50$ & $\$ 115.50$ \\
\hline 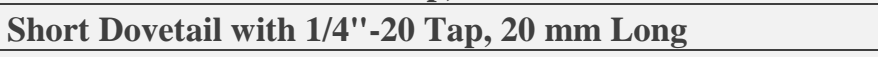 & XT66DE1 & 7 & $\$ 9.50$ & $\$ 66.50$ \\
\hline XT66 Double Dovetail Clamp, $40 \mathrm{~mm}$ & XT66C2 & 1 & $\$ 18.30$ & $\$ 18.30$ \\
\hline $\begin{array}{l}\text { Dovetail Mounting Platform for } 66 \text { mm Optical Rails, } 40 \\
\text { mm Long }\end{array}$ & XT66D2-40 & 1 & $\$ 14.00$ & $\$ 14.00$ \\
\hline Low-Profile T-Nut (1/4"'-20), 10 per Pack & XE25T3 & 1 & $\$ 9.60$ & $\$ 9.60$ \\
\hline & & & Sub Tot & $\$ 307.90$ \\
\hline Thorlabs Posts & Part Number & Quantity & Price & QxP \\
\hline $\begin{array}{l}\text { Post Holder with Spring-Loaded Hex Locking } \\
\text { Thumbscrew, L = 3.00" }\end{array}$ & PH3 & 5 & $\$ 8.27$ & $\$ 41.35$ \\
\hline $\begin{array}{l}\text { Ø1/2" x 3" Stainless Steel Optical Post, 8-32 Stud, 1/4"-20 } \\
\text { Tapped Hole }\end{array}$ & TR3 & 5 & $\$ 5.42$ & $\$ 27.10$ \\
\hline $\begin{array}{l}\text { Post Holder with Spring-Loaded Hex Locking } \\
\text { Thumbscrew, L = 2.00" }\end{array}$ & PH2 & 1 & $\$ 7.70$ & $\$ 7.70$ \\
\hline $\begin{array}{l}\text { Ø1/2" x 2" Stainless Steel Optical Post, 8-32 Stud, 1/4"-20 } \\
\text { Tapped Hole }\end{array}$ & TR2 & 1 & $\$ 5.19$ & $\$ 5.19$ \\
\hline $\begin{array}{l}\text { Post Holder with Spring-Loaded Hex Locking } \\
\text { Thumbscrew, L = 1.00" }\end{array}$ & PH1 & 1 & $\$ 7.03$ & $\$ 7.03$ \\
\hline $\begin{array}{l}\text { Ø1/2" x 1" Stainless Steel Optical Post, 8-32 Stud, 1/4"-20 } \\
\text { Tapped Hole }\end{array}$ & TR1 & 1 & $\$ 4.74$ & $\$ 4.74$ \\
\hline \multicolumn{4}{|r|}{ Sub Tot } & $\$ 993.11$ \\
\hline Thorlabs Laser Diode & Part Number & Quantity & Price & QxP \\
\hline
\end{tabular}




\begin{tabular}{|c|c|c|c|c|}
\hline $\begin{array}{l}\text { Collimated Laser Diode Module, } 532 \mathrm{~nm}, 4.5 \mathrm{~mW} \text {, Round } \\
\text { Beam }\end{array}$ & CP532 & 1 & $\$ 155.00$ & $\$ 155.00$ \\
\hline SM1 Adapter for $\emptyset 11 \mathrm{~mm}$ Collimators & AD11F & 1 & $\$ 27.00$ & $\$ 27.00$ \\
\hline SM1-Threaded Kinematic Mount for Thin Ø1" Optics & KM100T & 1 & $\$ 64.00$ & $\$ 64.00$ \\
\hline 5 VDC Regulated Power Supply, 2.5 mm Phono Plug & LDS5 & 1 & $\$ 83.35$ & $\$ 83.35$ \\
\hline \multicolumn{4}{|r|}{ Sub Tot } & $\$ 329.35$ \\
\hline Thorlabs Spatial Filter & Part Number & Quantity & Price & QxP \\
\hline XY Translator with Micrometer Drives & ST1XY-S & 1 & $\$ 344.60$ & $\$ 344.60$ \\
\hline Z-Axis Translation Mount, One Retaining Ring Included & SM1Z & 1 & $\$ 176.00$ & $\$ 176.00$ \\
\hline $30 \mathrm{~mm}$ Cage System Alignment Plate with $\emptyset 1 \mathrm{~mm}$ Hole & CPA1 & 1 & $\$ 12.00$ & $\$ 12.00$ \\
\hline Cage Assembly Rod, 2" Long, Ø6 mm, Qty. 1 & ER2 & 4 & $\$ 6.10$ & $\$ 24.40$ \\
\hline Extended RMS to M9 x 0.5 Adapter & E09RMS & 1 & $\$ 32.00$ & $\$ 32.00$ \\
\hline $\begin{array}{l}\text { Adapter with External SM1 Threads and Internal RMS } \\
\text { Threads }\end{array}$ & SM1A3 & 1 & $\$ 16.75$ & $\$ 16.75$ \\
\hline $\begin{array}{l}\text { Ø1.5" Post Mounting Adapter, 1/4" Clearance / \#8 } \\
\text { Clearance }\end{array}$ & MA2 & 1 & $\$ 16.00$ & $\$ 16.00$ \\
\hline Ø1.5" Mounting Post, Length=3", 1/4"-20 Taps & $\mathbf{P 3}$ & 1 & $\$ 33.00$ & $\$ 33.00$ \\
\hline $\begin{array}{l}\emptyset 10 \mu \mathrm{m} \text { Mounted Pinhole, Ideal For Building Spatial } \\
\text { Filters }\end{array}$ & P10S & 1 & $\$ 70.00$ & $\$ 70.00$ \\
\hline $\begin{array}{l}f=11.0 \mathrm{~mm}, \mathrm{NA}=0.26, \text { Mounted Aspheric Lens, AR: } \\
350-700 \mathrm{~nm}\end{array}$ & A220TM-A & 1 & $\$ 87.00$ & $\$ 87.00$ \\
\hline \multicolumn{4}{|r|}{ Sub Tot } & $\$ 811.75$ \\
\hline Thorlabs Lenses and Lens Mounts & Part Number & Quantity & Price & QxP \\
\hline Lens Mount for Ø2" Optics, One Retaining Ring Included & LMR2 & 2 & $\$ 23.50$ & $\$ 47.00$ \\
\hline Lens Mount for Ø1" Optics, One Retaining Ring Included & LMR1 & 2 & $\$ 15.70$ & $\$ 31.40$ \\
\hline $\begin{array}{l}\text { N-BK7 Plano-Convex Lens, Ø1", f = } 25.4 \text { mm, ARC: 350- } \\
700 \text { nm }\end{array}$ & LA1951-A & 1 & $\$ 31.80$ & $\$ 31.80$ \\
\hline $\begin{array}{l}\text { N-BK7 Plano-Convex Lens, Ø50.8 mm, } \mathrm{f}=75.0 \mathrm{~mm} \text {, } \\
\text { ARC: } 350-700 \mathrm{~nm}\end{array}$ & LA1145-A & 2 & $\$ 39.80$ & $\$ 79.60$ \\
\hline \multicolumn{4}{|r|}{ Sub Tot } & $\$ 189.80$ \\
\hline Thorlabs Various Parts & Part Number & Quantity & Price & QxP \\
\hline SM1 Lens Tube, L = 0.3", One Retaining Ring Included & SM1L30 & 1 & $\$ 12.16$ & $\$ 12.16$ \\
\hline SM1 Lens Tube, L = 3", One Retaining Ring Included & SM130 & 1 & $\$ 25.75$ & $\$ 25.75$ \\
\hline Filter Holder for 2" Square Filters, Stackable & FH2 & 2 & $\$ 18.00$ & $\$ 36.00$ \\
\hline \multicolumn{4}{|r|}{ Sub Tot } & $\$ 73.91$ \\
\hline Custom Parts & Part Number & Quantity & Price & QxP \\
\hline 12 Volt DC Motor, 50 RPM, Ø25.0 mm & N/A & 1 & $\$ 10.00$ & $\$ 10.00$ \\
\hline $\begin{array}{l}\text { Hobby Transformer, Input } 120 \text { V AC } 60 \mathrm{~Hz} \text {, Output } 18 \mathrm{~V} \\
\text { DC }\end{array}$ & N/A & 1 & $\$ 25.00$ & $\$ 25.00$ \\
\hline Custom machined CD/Motor mount & N/A & 1 & $\$ 10.00$ & $\$ 10.00$ \\
\hline Transparency Films and Printing & N/A & 1 & $\$ 10.00$ & $\$ 10.00$ \\
\hline & & & Sub Tot & $\$ 55.00$ \\
\hline & & & Total & $\$ 1,860.82$ \\
\hline
\end{tabular}




\section{REFERENCES}

1 Andrews, L. C., [Field Guide to Atmospheric Optics], SPIE Press (2004).

2 Tyson, R. K., Frazier, B. W., [Field Guide to Adaptive Optics, $2^{\text {nd }}$ Ed.], SPIE Press (2012).

3 Spencer, M. F., Cusumano, S. J., Schmidt, J. D., and Fiorino, S. T., "Impact of spatial resolution on thermal blooming phase compensation instability," Proc. SPIE 7816, 781609 (2010).

4 Spencer, M. F., Cusumano, S. J., "Impact of branch points in adaptive optics compensation of thermal blooming and turbulence," Proc. SPIE 8165, 816503 (2011).

5 Perram, G. P., Cusumano, S. J., Hengehold, R. L., and Fiorino, S. T., [Introduction to Laser Weapon Systems], Directed Energy Professional Society (2010).

6 Pellizzari, C., Spencer, M., Steinhoff, N., Belsher, J., Tyler, G., Williams, S., and Williams, S., “ Inverese synthetic aperture ladar: a high-fidelity modeling and simulation tool," Proc. SPIE 8877, 88770B (2013).

7 Pellizzari, C. J., Spencer, M. F., Calef, B., Bos, J., Senft, D. C., William, S., and Williams, S. E., "Performance characterization of Phase Gradient Autofocus for inverse synthetic aperture LADAR," Proc. IEEE 14384400, 1-11 (2014).

8 Schmidt, J. D., [Numerical Simulation of Optical Wave Propagation with Example in MATLAB], SPIE Press (2010).

9 Rampy, R., Gavel, D., Dillon, D., and Thomas, S., "Production of phase screens for simulation of atmospheric turbulence," App. Opt. 51, 8769-8778 (2012).

10 Verdeyen, J. T., [Laser Electronics, $3^{\text {rd }}$ Ed.], Prentice Hall (1995).

11 Hogge, C. B., and Butts, R. R., "Effects of using different wavelengths in wave-front sensing and correction," J. Opt. Soc. Am. 72, 606-609 (1982).

12 Note that overspray works best to lightly coat the clear $\mathrm{cd}$. The goal is to make phase screen not a diffuser! 